\title{
THERMAL REMOTE SENSING OF URBAN CLIMATES IN SOUTH AFRICA THROUGH THE MONO-WINDOW ALGORITHM
}

\author{
Adeline Ngie \\ AQCCI: Unit for Env. Sc. and Management, School of Geo-and Spatial Sciences, Faculty of Natural and Agricultural Sciences, \\ North - West University, South Africa: adeline.ngie@nwu.ac.za
}

KEY WORDS: Urban heat islands • thermal remote sensing • land surface temperature $\bullet$ Landsat ETM+

\begin{abstract}
:
Urban Heat Island (UHI) is among some of the challenges plaguing urban environments. There is increase human population within urban environments especially in the developing world, which is a need to understand the climates for their wellbeing. The use of multispectral satellite remote sensing to investigate the climatic conditions through radiation measurement is applied across the two major South African cities. The thermal remote sensing technique applied for this study is the direct determination of land surface temperatures (LST) using multispectral thermal imagery (ETM+). In addition, meteorological data which included air temperature and relative humidity for the same satellite image dates were used. The LST values obtained showed Johannesburg has many micro heat islands scattered across the metro than in Cape Town. These areas of heat islands corresponded to areas of human settlement and more so the unplanned as opposed to the planned ones. The estimated LST values and observed air temperature values with an $\mathrm{R}^{2}$ of 0.9 . It could be concluded that expansion of urban areas in South Africa has led to increased thermal radiation of land surface in densely populated areas.
\end{abstract}

\section{INTRODUCTION}

Urbanisation is a phenomenon of change in landuse type by humans for their well being. One of its key aspects is the reduction in vegetation cover and an increase in concreted or paved areas. Increasing urbanisation especially in the developing countries as South Africa, is continuously challenging for town planners and policy makers to incorporate knowledge about climatic conditions within urban spaces and manage towards minimal impacts on human health (Orimoloye et al., 2018). In which case it would be even more difficult for countries like South Africa where these urban spaces are invaded by unplanned settlements which make use of corrugated sheets to construct houses and have no home-garden spaces (Chikoto, 2009). Therefore, it is but essential that studies be conducted for a spatio-temporal appraisal of some climatic parameters such as surface temperature.

One of the important characteristics of urban environments is impervious paved surfaces and reduced vegetation. This characteristic causes more of the sun's incoming radiant energy to be reflected from urban areas and, less of it is converted to latent energy involved in evaporation or transpiration of moisture (Taha, 1997). The larger volume of asphalt, brick, concrete, and other materials in urban areas give it a higher thermal storage capacity than surrounding vegetated surfaces. The urban canopy also stores large amounts of energy during the day which it releases at night (Oke, 1987). Another factor exacerbating relatively high temperatures within urban areas than its surroundings is the additional heat generated by automobiles, air conditioning and other machinery.

The UHI has been described as one of the major challengers to sustainable livelihood within urban areas. The UHI is the excess temperature near the ground (canopy layer) of the central urban locations as being higher than those of nearby or surrounding areas (Voogt and Oke, 2003). This phenomenon has previously been considered as the difference between urban and rural areas but with recent developments in cities, there is no distinct borderline between 'urban' and 'rural' areas as a result of urban growth (Voogt, 2004). In recent times it has been considered as the difference between the central parts of the city and its surrounding areas (Ngie et al., 2014). The continuous urbanisation of urban areas has led to various settlement areas across metropolitan cities and is a motivation for this study.

Therefore, this study sought to assess the spatio-temporal display of surface temperature across two major metropolitan cities of South Africa with both planned and unplanned settlements. This made used of the mono-window algorithm in estimating LST (Qin et al., 2001) for Johannesburg and Cape Town metros. There will be a highlight of surface temperature situation across these metropolitan cities.

\section{STUDY AREA AND DATA COLLECTION}

Urban areas in post-apartheid South Africa where movement of people is no longer restricted have experienced tremendous growth rates (Ndebele, 2013). According to the last national census, the country experienced a $15.5 \%$ population growth from 2001 to 2011 meanwhile some provinces like Gauteng (seat to the city of Johannesburg) experienced a $33.7 \%$ increase within the same 10-year period being double the national average (Stats SA, 2012). Based on their rapid rate of urbanisation the two major cities were selected for this investigation (Figure 1).

\subsection{Study Area}

In terms of population and economic status, Johannesburg is the biggest city in South Africa with huge urban sprawl problems influenced by highly linked highway interchanges. On a land surface area of $1645 \mathrm{~km}^{2}$ the city supports a population of 4434827 inhabitants. Cape Town is the second largest with 3740026 inhabitants on a total land area of $2455 \mathrm{~km}^{2}$ (census 2011: Stats SA, 2012). 


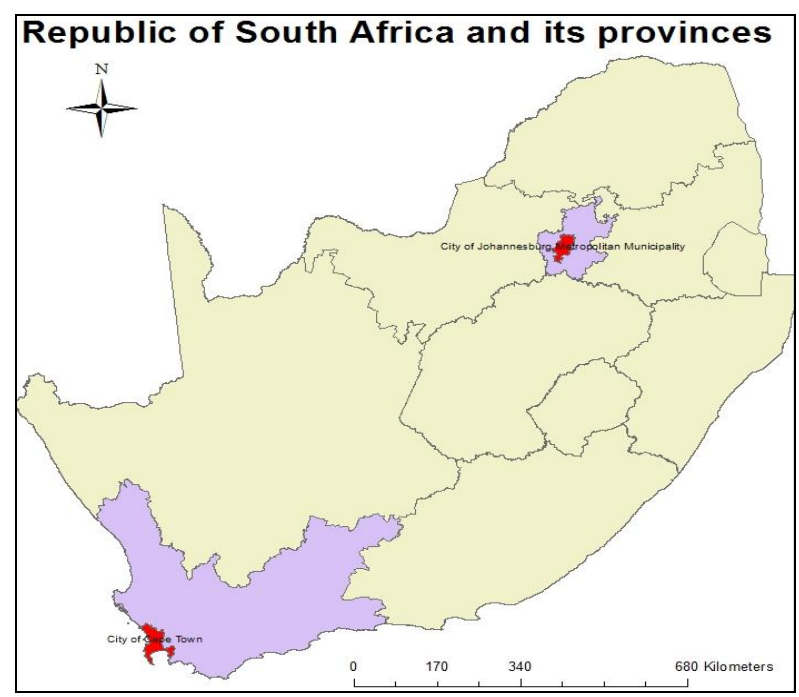

Figure 1: Map of South Africa showing the 2 cities

\subsection{Data}

2.2.1 Satellite Imagery: Satellite data were acquired over two different seasons: winter (June-August) and summer (January-March) during the day periods for each season for two different years. The years selected were 2002 and 2012. Where suitable 2012 images were not available (due to high cloud cover), 2011 images within the same season were acquired. For instance, summer images over Cape Town were selected in 2011. Therefore, a total of 8 LANDSAT ETM+ images were acquired for the study by downloaded from the United States Geological Society (USGS) website.

2.2.2 Other Auxiliary Data: The weather data were obtained from South African Weather Service. These data included air temperature and relative humidity ( Table 1). Daily measurements for the required dates of satellite images were obtained. The air temperature and relative humidity data were used for the analysis.

\subsection{Data Pre-Processing}

The Enhanced Thematic Mapper Plus (ETM+) data was acquired through the USGS website after a thorough search of available and cloud free scenes for both the winter and summer seasons of the years of study. The downloaded data was unzipped then for those that have no gaps, layer stacking and clipping of study areas were done using ENVI version 5.01.

The Scan Line Corrector (SLC) which compensates for the forward motion of ETM+ on Landsat 7 failed on May 31, 2003 and recovery efforts were unsuccessful. ETM+ now traces a zig-zag pattern along the satellite ground track with striped images of increasing strip width towards the scene edge. An estimated $22 \%$ of any given scene is lost because of the SLC failure and precise locations of the missing scan lines will vary from scene to scene (Landsat 7 Science Data Users Handbook ${ }^{2}$ ).

Therefore, the acquired ETM+ images post 2003 had to undergo gap filling using different scenes of the same Landsat ETM+ sensors from different adjacent dates of acquisition. These dates fall into the same season being investigated. The gap filling module developed in ERDAS Imagine ${ }^{\circledR}$ was applied. This module operates on two functions; to fetch gaps existing on the given scene for the first image, and to match the histogram for the gaps from the scene of the second image.

The separate image bands were combined into a single multispectral image file to serve as input into the algorithm. This is known as layer stacking and also commonly used to combine image derivatives with spectral bands for further analysis. The images were clipped to the desired study areas (municipal boundaries of the cities which are metropolitan).

\section{METHODOLOGY}

\subsection{LST retrieval methods}

The UHI effect has been studied through the retrieval of LST from satellite remote sensing data (Voogt \& Oke, 2003; Mirzaei \& Haghighat, 2010; Ngie et al., 2014; Abutaleb et al., 2015; Ngie et al., 2016; Sharma \& Bisht, 2019). Landsat TM and ETM+ have a single thermal band (band 6) which is the thermal infrared (TIR) channel that records radiation within a 10.4$12.5 \mu \mathrm{m}$ spectral range. Different LST retrieval methods have been developed according to different data sources (thermal bands on a sensor), such as the split-window, temperature/emissivity separation, mono-window, and the single-channel methods (Qin et al., 2001, Sobrino et al., 1996; Jimenez-Munoz \& Sobrino, 2003). Among these methods three can be applied to Landsat data; these include the radiative transfer equation, mono-window algorithm and single-channel algorithm.

Although all of these methods can provide good results, some of them such as the radiative transfer equation can only yield results with in situ atmospheric parameters captured simultaneously as the satellite passes over the study area. In addition, the mono-window algorithm can get better results than the single-channel algorithm with a root mean square deviation of $0.9^{\circ} \mathrm{C}$ (Sobrino, et. al., 2004). It has proven to yield better accuracy for the retrieval of LST from Landsat images as illustrated for Hong Kong with a $0.7^{\circ} \mathrm{C}$ error (Liu \& Zhang, 2011).

This study therefore makes use of the mono-window algorithm to retrieve the LST from the ETM+ imagery for the cities of Johannesburg and Cape Town. The algorithm is based on thermal radiance transfer equation and only requires three parameters: emissivity, transmittance and effective mean atmospheric temperature to retrieve LST from Landsat multispectral imagery (Qin et al., 2001). The model was designed using ERDAS Imagine ${ }^{\circledR}$ spatial model tool (Sun et al., 2010; Liu \& Zhang, 2011). It required two measured parameters: near-surface air temperature and relative humidity (RH) simultaneously measured as the satellite passed over the study area. These data were obtained from the local weather stations situated within the study areas ( Table 1). The two parameters were then converted to atmospheric transmittance and effective mean atmospheric temperature. The third parameter (emissivity) was calculated from the normalized difference vegetation index (NDVI).

\footnotetext{
1 Exelis Visual Information Solutions. 2010. Name of the manual

Boulder, Colorado: Exelis Visual Information Solutions.

${ }^{2}$ http://landsathandbook.gsf.nasa.gov/ Accessed 19/11/2016
} 


\begin{tabular}{|c|c|c|c|c|c|c|c|c|c|c|}
\hline CITY & DATE & MAX_TEMP & MIN_TEMP & MIN_RH & MAX_RH & $\begin{array}{l}\text { Water } \\
\text { Vapour }\end{array}$ & \multicolumn{4}{|c|}{ TRANSMITTANCE } \\
\hline \multirow{4}{*}{ Johannesburg } & January $7^{\text {th }} 2002$ & 22 & 20 & 65 & 84 & 1.904 & 0.822 & 0.799 & 0.812 & 0.784 \\
\hline & July $2^{\text {nd }} 2002$ & 6 & 5 & 76 & 100 & 0.814 & 0.909 & 0.904 & 0.937 & 0.939 \\
\hline & January $3^{\text {rd }} 2012$ & 24 & 21 & 56 & 70 & 1.752 & 0.834 & 0.814 & 0.829 & 0.806 \\
\hline & June $27^{\text {th }} 2012$ & 7 & 6 & 50 & 65 & 0.575 & 0.928 & 0.927 & 0.965 & 0.972 \\
\hline \multirow{4}{*}{ Cape Town } & March 15th 2002 & 26 & 13 & 89 & 97 & 2.286 & 0.791 & 0.762 & 0.768 & 0.730 \\
\hline & July $21^{\text {st }} 2002$ & 24 & 13 & 42 & 84 & 1.275 & 0.872 & 0.860 & 0.884 & 0.873 \\
\hline & March $26^{\text {th }} 2012$ & 28 & 15 & 64 & 93 & 2.033 & 0.811 & 0.787 & 0.797 & 0.766 \\
\hline & June $12^{\text {th }} 2011$ & 20 & 2 & 74 & 99 & 1.214 & 0.877 & 0.865 & 0.891 & 0.882 \\
\hline
\end{tabular}

Table 1: Satellite and auxiliary data collected and estimated parameters (water vapour content and transmittance)

\subsection{Mono-window algorithm}

3.2.1 Conversion of digital number into spectral radiance: The satellite sensors measure reflectance from the earth surface as digital numbers (DN) representing every pixel of the image. The DN data from Landsat was converted to spectral radiance using Equation (1):

$$
L_{\lambda}=L_{\lambda \min }+\left(L_{\lambda \max }-L_{\lambda \min }\right) \times \frac{\left(Q_{\lambda D N}-Q_{\lambda \min }\right)}{\left(Q_{\lambda \max }-Q_{\lambda \min }\right)}
$$

Where $L_{\lambda} \mathrm{L}$ is at-sensor spectral radiance;

$L_{\lambda \max } \mathrm{L}$ is maximum at-sensor spectral radiance;

$L_{\lambda \min } \mathrm{L}$ is minimum at-sensor spectral radiance;

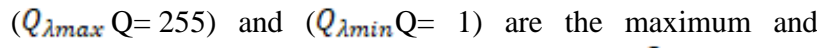
minimum $D N$ value of pixels respectively and, $Q_{\lambda D N} \mathrm{Q}$ is the DN value of pixel.

For Landsat $\mathrm{ETM}^{+}$data, equation (1) can be rewritten in two dimensions depending on the low and high gain bands of the thermal band and expressed in equations 2 and 3 .

1 The low gain band which provides an expanded dynamic range with lower radiometric resolution (sensitivity), has less saturation at high DN values ${ }^{3}$ and expressed thus:

$$
L_{61}=0.0671\left(Q_{\lambda D N}-1\right)
$$

2 The high gain band has a higher radiometric resolution (sensitivity) although it has a more restricted dynamic range (ibid) and expressed thus:

$$
L_{62}=0.0372\left(Q_{\lambda D N}-1\right)+3.2
$$

3.2.2 Conversion of spectral radiance into at-sensor brightness temperature: The conversion formula is:

$$
T_{i}=\frac{K_{2}}{\ln \left[\frac{K_{1}}{L_{\Omega}}+1\right]}
$$

\footnotetext{
${ }^{3}$ http://landsathandbook.gsfc.nasa.gov/data_properties/prog_sect6_4.ht
} ml. Accessed 27/02/2014
Where $T_{i}$ is at-sensor temperature in Kelvin, $\mathrm{K}_{1}$ and $\mathrm{K}_{2}$ are prelaunch calibration constants and, $\mathrm{L}_{\lambda}$ is the spectral radiance in watts per metre squared steradian micron $\left(\mathrm{W} /\left(\mathrm{m}^{2 *} \mathrm{sr} * \mu \mathrm{m}\right)\right)$. For $\mathrm{ETM}+$ the calibration constants are:

$$
\begin{aligned}
& K_{1}=666.09\left(\mathrm{~W} /\left(\mathrm{m}^{2 *} \mathrm{sr}^{*} \mu \mathrm{m}\right)\right) \\
& K_{2}=1282.71 \mathrm{~K}
\end{aligned}
$$

3.2.3 Calculation of NDVI: NDVI is a simple graphical indicator usually used to analyze remote sensing measurements, and assess if observed target includes green vegetation or not. NDVI is one of the outputs that run into the model to retrieve LST. Therefore, eight NDVI maps were produced according to the various dates of satellite capture in this study using equation (5)

$$
N D V I=\frac{\mathrm{NIR}-\mathrm{R}}{\mathrm{NIR}+\mathrm{R}}
$$

Where NIR is Near Infra-red band and $\mathrm{R}$ is the red band

3.2.4 Estimation of emissivity: In this study, the land surface emissivity was derived from the NDVI (Zhang, 2006). From the NDVI results obtained above (Equation 5) corresponding land emissivity values were established (Table 2).

\begin{tabular}{|c|c|}
\hline NDVI & $\begin{array}{c}\text { Land surface emissivity } \\
\left(\varepsilon_{\mathrm{i}}\right)\end{array}$ \\
\hline NDVI $<-0.185$ & 0.995 \\
\hline$-0.185 \leq \mathrm{NDVI}<$ & 0.970 \\
0.157 & \\
\hline $0.157 \leq \mathrm{NDVI} \leq$ & $1.0094+0.0047^{*}$ \\
0.727 & Ln(NDVI) \\
\hline NDVI $>0.727$ & 0.990 \\
\hline
\end{tabular}

Table 2: Estimation of land surface emissivity from NDVI (Adopted from Zhang, 2006)

3.2.5 Estimation of atmospheric transmittance: Atmospheric transmittance which is defined as the capacity of the atmosphere to transmit electromagnetic energy is dependent on the air mass penetrated by radiations, as well as on the amount of water vapour and dust in the air. It varies for radiations of different wavelengths; the smaller the atmospheric absorption and scattering of light, the greater the atmospheric transmittance.

3.2.6 Calculation of water vapour content: The calculation of water vapour is done through equation (6) which entails deriving relative humidity. Relative humidity can be defined as the ratio of water vapour at a given temperature to the saturation water vapour pressure at the same temperature (Wagner and Pruß, 2002).

$R H=\frac{P_{a}}{P_{s}} \times 100$ 
Where RH is the relative humidity;

$P_{a}$ is the actual water vapour pressure;

$P_{s}$ is the saturation water vapour pressure.

Equation (6) is rewritten to obtain $\mathrm{P}_{\mathrm{a}}$ as follows:

$P_{a}=P_{s} \frac{R H}{100}$

The saturation water vapour pressure $\left(P_{s}\right)$ at a given temperature (K) can be calculated (Wagner and Pruß, 2002):

$\boldsymbol{P}_{s}=\boldsymbol{P}_{c} * e^{\left[\frac{T_{c}}{T}\left(c_{1} \vartheta+c_{2} \theta^{1.5}+c_{3} \vartheta^{3}+c_{4} \vartheta^{3.5}+c_{5} \theta^{4}+c_{6} \vartheta^{7.5}\right)\right]}$

Where:

$\mathrm{T}=$ ambient temperature in $\mathrm{K}$

$\mathrm{P}_{\mathrm{s}}=$ Saturation water vapour pressure $(\mathrm{hPa})$

$\mathrm{T}_{\mathrm{c}}=$ Water critical temperature $(647.096 \mathrm{~K})$

$\mathrm{P}_{\mathrm{c}}=$ Critical pressure $(220640 \mathrm{hPa})$

$\mathrm{C}_{1}=-7.85951783$

$\mathrm{C}_{2}=1.84408259$

$\mathrm{C}_{3}=-11.7866497$

$\mathrm{C}_{4}=22.6807411$

$\mathrm{C}_{5}=-15.9618719$

$\mathrm{C}_{6}=1.80122502$

And

$$
\vartheta=1-\frac{T}{T_{c}}
$$

Atmospheric transmittance is then estimated on the basis of some linear equations derived from statistical regression analysis (Qin et al., 2001). These equations relate the atmospheric transmittance to the water vapour content $\left(\mathrm{g} / \mathrm{cm}^{2}\right)$ (Equation (8)). Based on the results obtained for water vapour content in this study, corresponding atmospheric transmittance equations were selected (Error! Reference source not found.). The air temperature $\left(t_{a}\right)$ profiles were set as $t_{a}<15^{\circ} \mathrm{C}$ being low and $t_{a}>15^{\circ} \mathrm{C}$ as being high.

3.2.7 Calculation of mean atmospheric temperature: Equations (9) and (10) are used to estimate the atmospheric mean temperature $\left(\mathrm{T}_{\mathrm{a}}\right)$ based on given near surface air temperature (Qin et al., 2001):

For mid-latitude summer

$$
T_{a}=16.0110+0.92621 T_{0}
$$

For mid-latitude winter

$$
T_{a}=19.2704+0.91118 T_{0}
$$

LST retrieval from the mono-window algorithm: In the monowindow algorithm, the LST value is calculated using Equation 11 but with two unknowns (C and $\mathrm{D})$ being realised through Equations 12 and 13. The three required parameters (emissivity, transmittance and effective mean atmospheric temperature) are included in the equation as follows:

$$
\begin{aligned}
& T_{s}=\frac{\left(a+b T_{i}\right)(1-C-D)+D\left(T_{i}-T_{a}\right)}{c}+T_{i} \\
& D=\left(1-\varepsilon_{i}\right)\left[1+\left(1-\varepsilon_{i}\right) t\right] \\
& C=\varepsilon_{i} * t
\end{aligned}
$$

Where: $T_{\bar{s}}$ is $\operatorname{LST}(\mathrm{K}) ; T_{i}$ is at-sensor temperature $(\mathrm{K})$; $\varepsilon_{\tilde{i}}$ is emissivity estimated from NDVI; $t$ is atmospheric transmittance calculated from water vapour content; $T_{a}$ is mean atmospheric temperature; $a=-67.355351$, and $\mathrm{b}=0.458606$.

\section{RESULTS AND DISCUSSION}

\subsection{Relationship between the observed air temperature and the estimated LST}

Statistical regression analysis was used to establish a relationship between the estimated LST values and the measured air temperature values from weather stations in the two cities. The analysis was done using mean temperature values for both scenarios over the cities and seasons. The results yielded an $\mathrm{R}^{2}$ of 0.9 . Therefore, results confirmed the fitness of the mono-window algorithm in estimating LST values. The difference between the estimated LST values and the measured air temperature values can be associated partly with the effects of surface roughness on surface temperature and emissivity not considered (Weng, 2001) and partly because of atmospheric impurities which can obstruct the smooth passage of radiant energy (Brooks, 2006).

\subsection{Spatial distribution of surface temperature}

The spatial distribution of surface temperatures from these two cities indicated that not just do the central city regions illustrate heat islands but also around the cities which correlated to the informal human settlement areas. The intensity of these heat islands varied within these cities and the various areas.

In Cape Town the city centre showed a surface temperature increase to a maximum of $5^{\circ} \mathrm{C}$ compared to the surroundings in summer 2012 (Figure 2). However, the geographical features surrounding this city being the Table Mountain in the south and the ocean (Atlantic and Indian Oceans) to the east and west respectively should play a role in the experience but require further research to ascertain. 


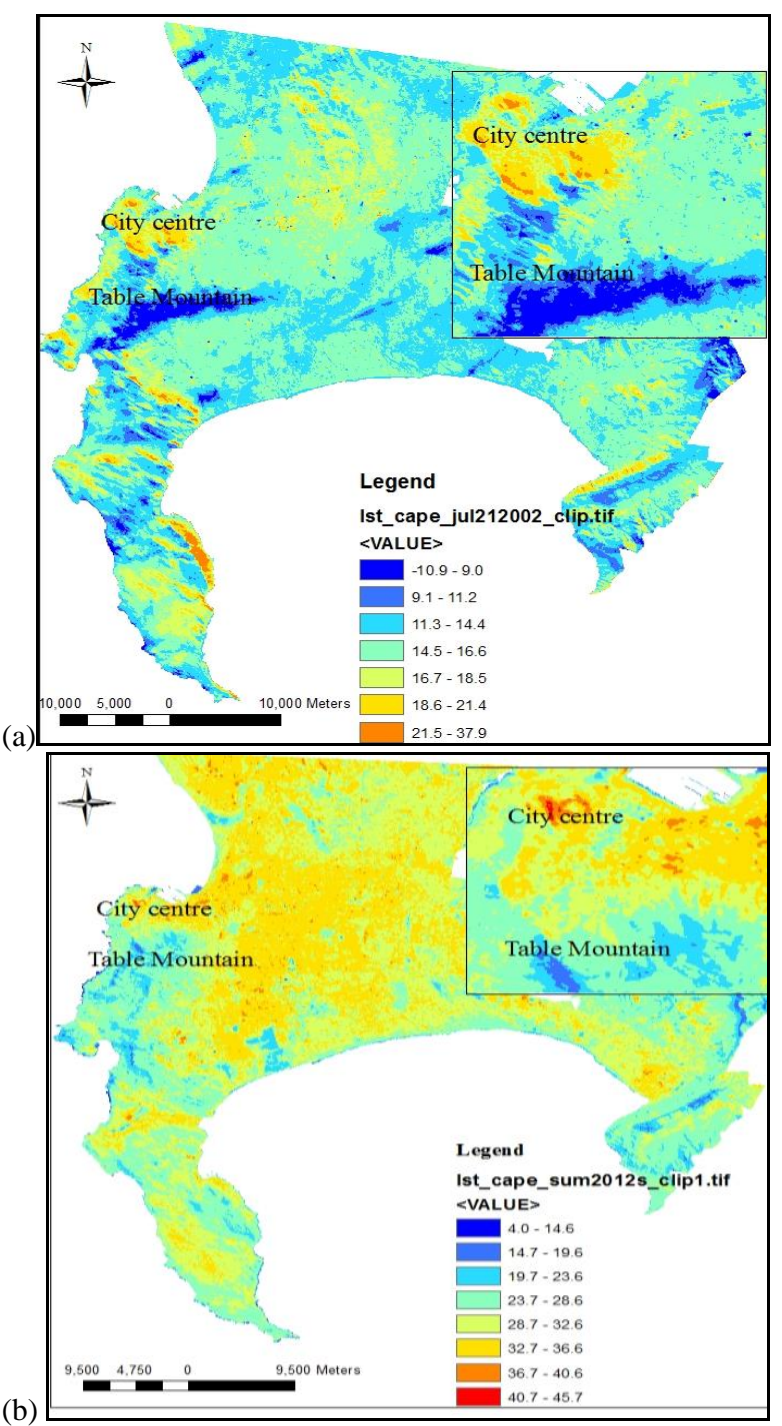

Figure 2: LST maps for Cape Town (a) Winter 2002; (b) Summer 2012

When new surface materials which include asphalt and concrete are introduced to a naturally vegetated area the thermal climate also changes with an increase in canopy temperature. The emission of heat, moisture and pollutants dramatically change radiative, thermal, moisture, roughness and emissions properties of the surface and the atmosphere above (Joshi \& Bhatt, 2012). There is also the emission of a lot of radiant energy through automobiles and heavy machines within these urban centres which contributes in the higher LST values (Figure 3).

Generally, the intensity of surface temperature in Johannesburg is at micro levels due to the high density of planted trees which do not only absorb the energy but cause shaded areas that disrupt the heat island (Liu et al., 2007). There are other major centres of heat islands in Johannesburg which could be linked to the expansion of urban areas with or without necessary planning. The expansion of planned areas towards the northern parts of the city, distinctively shows the Sandton, Fourways and Randburg city centres. However, the unplanned and unorganized rapid expansions of settlements such as the Alexandra Township in the north as well and SOWETO in the south western section illustrate heat island intensities slightly higher than their planned human settlements (Figure 3). For instance, Sandton which is adjacent to Alexandra but is a formally planned up-market area experiences a $2^{\circ} \mathrm{C}$ lower land surface temperature.

This study highlighted the fact that it is not just a challenge with development that has transformed vegetated areas to paved or concreted land covers but also that of land use. The human activities within these unplanned settlements which include burning coal for cooking as well as heating in open fires can be seen as contributors to raising the surface temperature. These unplanned settlements have limited land space for vegetation due to the high influx of people from rural to urban areas without any resources to live within decent or planned neighbourhoods (Chikoto, 2009). They end up raising structures with metal sheets and of high density as is the case with the informal sections of the south western part of Johannesburg (SOWETO), Alexandra and other associated townships in the north eastern sections contributing to the higher LST values over those areas (Figure 3).

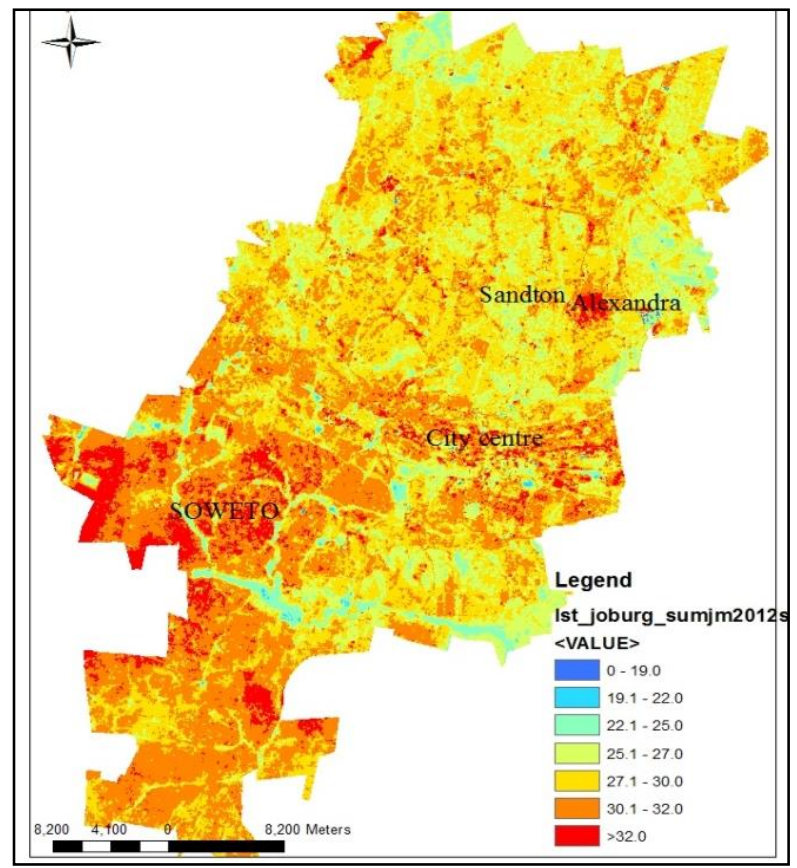

Figure 3: LST map of summer 2012 for Johannesburg

Another interesting observation for the city of Johannesburg is that the presence of mine tailings offer a cooling effect within the city centre as illustrated by the LST values over them (Figure 3). However, the rehabilitation process (introduction of vegetation) of these tailings has provided more assistance in regulating the urban temperatures. Li et al. (2011) studied the relationship of LST to NDVI and vegetation fraction and indicated that subsurface temperatures are linked to land-use and the vegetated areas act as heat sinks.

Human settlements have replaced existing vegetation with paved surfaces, which results in the sun's energy heating the man-made surfaces rather than being absorbed by vegetation and used for evapotranspiration (Taha, 1997) is considered prime cause of the UHI effect over these cities. The hottest temperatures were generally found in areas with the least vegetation (NDVI) and the greatest urban development. There is a strong relationship between LST and impervious surfaces as revealed in this study. This contributes to a large extent of the heat island problem thereby suggesting that town planners need to structure built-up areas with diverse structures and 
interspersed vegetation as well as water bodies in varying percentages to serve as the heat sinks and regulating urban climates (Zhang et al., 2008).

There also exist some situations of anomalies in this study where the city centre of Johannesburg seems to be cooler than its surrounding areas in winter but with a well-developed UHI in summer (Figure 3). This is however, not strange as it confirms some empirical generalizations offered by Oke (1982). These generalizations include the UHI intensity being most well developed in summer or in the warm half of the year and that the UHI may disappear by day or the city may be cooler than the rural (surrounding) environs. However, there will be need for further research to investigate the factors contributing to these situations.

\section{CONCLUSION}

The mono-window algorithm provided a simple and highly effective method for retrieving land surface temperatures for the analysis over these cities. This affirms other similar studies elsewhere in the world which have applied this algorithm (Ifatimehin \& Adeyemi, 2008; Lu et al., 2009; Liu \& Zhang, 2011; Khaled et al., 2015). The LST derived from the ETM+ thermal band depicted the spatial variability of land surface temperature of the cities of Johannesburg and Cape Town.

The spatial variability and intensity of the surface temperatures across the cities especially in Johannesburg illustrated the contribution from high urbanisation experience. There was a further distinction in the planned and unplanned or poorly planned expansions of urban centres. The intensities did not only vary by space or land use or land cover but also over seasons wherein for the Johannesburg the phenomenon is present in summer and absent in winter. There is a need to further look into the impact of geographical features around these cities such as mountains or oceans and also more validation stations to the high spatial variability which was supported by only two weather stations.

\section{ACKNOWLEDGEMENTS}

The author express appreciation to the anonymous reviewers.

\section{REFERENCES}

Abutaleb, K., A. Ngie, A. Darwish, M. Ahmed, S. Arafat and F. Ahmed, 2015: Assessment of Urban Heat Island using remotely sensed imagery over Greater Cairo, Egypt. Advances in Remote Sensing 4, 35-47

Arnfield, A.J., 2003: Two decades of urban climate research: a review of turbulence, exchanges of energy and water, and the urban heat island. International Journal of Climatology 23, 126.

Basar, U.G., S. Kaya and M. Karaca, 2008: Evaluation of urban heat island in Istanbul using remote sensing techniques. Commission VII, WG VII/5. The International Archives of the Photogrammetry, Remote Sensing and Spatial Information Sciences Vol. XXXVII. Part B7. Beijing.

Brooks, D. R., 2006: Monitoring Solar Radiation and Its Transmission through the Atmosphere. The GLOBE Program's Aerosols, Water Vapor, and UV-A Monitoring Projects V 2.0 http://www.pages.drexel.edu/ brooksdr/DRB/papers/UsingThe Sun/using.htm Accessed 20/11/2013.
Chikoto, T., 2009: Informal settlements in South Africa. Unpublished BSc (Hons) in Faculty of Engineering, Built Environment and Information technology, University of Pretoria, South Africa.

Ifatimehin, O.O. and S. Adeyemi, 2008: A satellite remote sensing based land surface temperature retrieval from Landsat TM data. Ethiopian Journal of Environmental Studies and Management 1(3), 63-70.

Jiménez-Muňoz, J.C. and J.A. Sobrino, 2003: A generalized single-channel method for retrieving land surface temperature from remote sensing data. Journal of Geophysical Research $108,4688-4694$.

Joshi, J.P. and B. Bhatt, 2012: Estimating temporal land surface temperature using remote sensing: A study of Vadodara urban area, Gujarat. International Journal of Geology, Earth and Environmental Sciences ISSN: 2277-2081 2(1), 123-130.

Landsberg, H.E., 1981: The Urban Climate. New York: Academic Press.

Li, J., C. Song, L. Cao, F. Zhu, X. Meng and J. Wu, 2011: Impacts of landscape structure on surface urban heat islands: A case study of Shanghai, China. Remote Sensing of Environment $115,3249-3263$.

Liu, L. and Y. Zhang, 2011: Urban Heat Island analysis using the Landsat TM data and ASTER Data: A case study in Hong Kong. Remote Sensing 3, 1535-1552.

Liu,W., C. Ji, J. Zhong, X. Jiang and Z. Zheng, 2007: Temporal Characteristics of the Beijing Urban Heat Island. Theoretical and Applied Climatology 87, 213-21.

Lowry, W. P., 1977: Empirical estimation of urban effects on climate: A problem analysis. Journal of Applied Meteorology 16(2), 129-135.

Lu, Y., P. Feng, C. Shen and J. Sun, 2009: Urban Heat Island in summer of Nanjing based on TM data. In Proceedings of 2009 Joint Urban Remote Sensing Event, Shanghai, China, 20-22 May; pp. 1-5.

Mirzaei, P.A. and F. Haghighat, 2010: Approaches to study Urban Heat Island - Abilities and limitations. Building and Environment 45, 2192-201.

Ndebele, T., 2013: South Africa goes with the urbanisation flow. Press release from the South African Institute of Race Relations (SAIRR). www.sairr.org.za Tel: 011-482-7221 Email: thuthukani@sairr.org.za.

Ngie, A., K. Abutaleb, F. Ahmed, A. Darwish and M. Ahmed, 2014: Assessment of Urban Heat Island using remotely sensed imagery: A Review. South African Geographical Journal. ID: 924864 DOI:10.1080/03736245.2014.924864

Ngie, A., K. Abutaleb, F. Ahmed, O.J. Taiwo, A. Darwish and M. Ahmed, 2016: An estimation of land surface temperature from Landsat ETM+ images for Durban, South Africa. Rwanda Journal, Series D, Volume 1, 2016, Life and Natural Sciences: Special issue II. http://dx.doi.org/10.4314/rj.v1i2S.2D

Oke, T.R., 1973: City size and the urban heat island. Atmospheric Environment 7, 769-779. 
Oke, T.R., 1982: The energetic basis of the urban heat island. Quarterly Journal of the Royal Meteorological Society 108, 124.

Oke, T.R., 1987: Boundary Layer Climates. New York: Routledge.

Orimoloye, I.R., S.P. Mazinyo, W. Nel, and A.M. Kalumba, 2018: Spatiotemporal monitoring of land surface temperature and estimated radiation using remote sensing: human health implications for East London, South Africa. Environmental Earth Sciences 77(3), 1 - 10.

Qin, Z., A. Karnieli and P. Berliner, 2001: A mono-window algorithm for retrieving land surface temperature from Landsat TM data and its application to the Israel-Egypt border region. International Journal of Remote Sensing 18, 3719-3746.

Sharma, V.R. and K. Bisht, 2019: Estimation of Land Surface Temperature using LANDSAT DATA: A case study of Agra city, India. International Journal of Advanced Research and Innovation of Ideas in Technology 5(2), 1850-1857.

Sobrino, J.A., J.C. Jimenez-Munoz and L. Paolini, 2004: Land surface temperature retrieval from LANDSAT TM 5. Remote Sensing of Environment 90, 434-440.

Sobrino, J.A., Z. L. Li, M.P. Stoll and F. Becker, 1996: Multichannel and multi-angle algorithms for estimating sea and land surface temperature with ASTER data. International Journal of Remote Sensing 17, 2089-2114.

Statistics South Africa (Stats SA), 2012: Census 2011 Statistical release- P0301.4/Statistics South Africa: Pretoria 78pp. www.statssa.gov.za

Sun, Q., J. Tan and Y. Xu, 2010: An ERDAS image processing method for retrieving LST and describing urban heat evolution: A case study in the Pearl River Delta Region in South China. Environment Earth Science 59, 1047-1055.

Taha, H., 1997: Urban climates and heat islands: Albedo, evapotranspiration and anthropogenic heat. Energy and Buildings 25, 99-103.

Voogt, J. A., 2004: Urban Heat Islands: Hotter Cities. American Institute of Biological Sciences. http://www.actionbioscience.org/environment/voogt.html Accessed 30/10/2013.

Voogt, J.A. and T.R. Oke, 2003: Thermal remote sensing of urban climates. Remote Sensing of Environment 86, 370-84.

Wagner, W. and A. Pruß, 2002: The IAPWS formulation 1995 for the thermodynamic properties of ordinary water substance for general and scientific use. Journal of Physical and Chemical Reference Data 31(2), pp. 387535.

Weng, Q., 2001: A remote Sensing-GIS evaluation of urban expansion and its impacts on surface temperature in the Zhujiang, Delta, China; International Journal of Remote Sensing 22(10), 1999-2014.

Zhang, Y., 2006: Land surface temperature retrieval from CBERS-02 IRMSS thermal infrared data and its applications in quantitative analysis of urban heat island effect. Journal of Remote Sensing 10, 789-797.

Zhang, Z., M. Ji, J. Shu, Z. Deng and Y. Wu, 2008: Surface urban heat island in Shanghai, China: Examining the relationship between land surface temperature and impervious surface fractions derived from Landsat ETM+ imagery. The International Archives of the Photogrammetry, Remote Sensing and Spatial Information Sciences. Vol. XXXVII. Part B8. Beijing. 